\title{
Continuous versus interrupted suture technique in microvascular anastomosis in rats ${ }^{1}$
}

Rui Sergio Monteiro de Barros', Rafael Aquino Leal", Renan Kleber Costa Teixeira"', Vitor Nagai

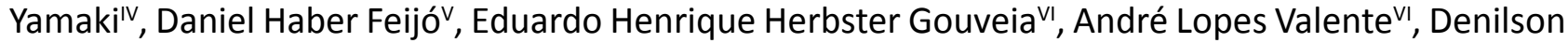
José Silva Feitosa-Juniorvi, Luan Teles Ferreira de Carvalhovı

'PhD, Associate Professor, Department of Experimental Surgery, School of Medicine, Universidade do Estado do Pará (UEPA), Belem-PA, Brazil. Conception, design, intellectual and scientific content of the study, critical revision.

"MD, Department of Experimental Surgery, School of Medicine, UEPA, Belem-PA, Brazil. Conception, design, intellectual and scientific content of the study; interpretation of data; manuscript writing.

II'Fellow Master degree, Postgraduate Program in Surgery and Experimental Research, UEPA, Belem-PA, Brazil. Interpretation of data, manuscript writing, critical revision.

${ }^{I V} \mathrm{MD}$, School of Medicine, UEPA, Belem-PA, Brazil. Acquisition and interpretation of data, statistical analysis.

${ }^{\vee}$ Graduate student, School of Medicine, UEPA, Belem-PA, Brazil. Interpretation of data.

${ }^{V} G$ raduate student, School of Medicine, UEPA, Belem-PA, Brazil. Acquisition and interpretation of data.

\section{Abstract}

Purpose: To compare the continuous and interrupted suture technique on femoral artery on rats after vessel repair and 14 days after.

Methods: Twenty rats were operated randomly divided into two group matched according to the suture technique used: interrupted or continuous. We performed a femoral anastomosis on the right femoral artery. We analyzed weight, arterial caliber, anastomosis time and patency after vessel repair and 14 days after.

Results: There was no significant difference between groups in the weight $(p=0.64)$, diameter of the femoral artery $(p=0.95)$ and patency $(p=1.00)$. The time spent in the anastomosis was 451 seconds in the continuous group and 718 seconds in the interrupted group, presenting significant difference $(p<0.01)$.

Conclusion: The continuous suture technique shows a similar patency rates than interrupted technique, however with a shorter time to perform the anastomosis.

Key words: Anastomosis, Surgical. Microsurgery. Rats. 


\section{Introduction}

Microvascular surgery is a challenging and requires sophisticated equipment and, perhaps more importantly, rigorous skill ${ }^{1}$. The crucial factor required for a successful microvascular surgical intervention is to produce patent vessels anastomoses; since, the successful on microvascular anastomoses is undoubtedly one of the most critical steps in performing free tissue transfer, limb replantation, and/or composite tissue allotransplantation ${ }^{1-3}$.

Ideally, anastomosis should be executed in a short time, protect integrity of intimal tissue, and avoid inflammatory response, stenosis, and thrombosis ${ }^{2,4}$. Overall, the simple interrupted suture technique is often so-called by many surgeons as the gold standard in endto-end microsurgical anastomoses ${ }^{4,5}$. Mainly, because studies until 1960s demonstrated the superiority of this technique over the others suturing technique. However, after 1970s, a lot of studies refuted this data and reported similar patency rates using a continuous suture technique ${ }^{4-7}$.

The continuous suture technique can save vascular anastomosis time over interrupted technique, and it has the advantage of swiftly reperfusing the involved tissues under conditions in which time is a factor ${ }^{7,8}$. Since the technique exerts compression circumferentially, anastomosis is less likely to leak. Nevertheless, it possesses certain disadvantages, such as lumen stenosis and formation of a rigid ring at the anastomosis site, as well as difficulties in elimination of vessel size discrepancy and leaves a greater amount of suture material in contact with the bloodstream, potentially leading to stasis and thrombosis $^{6,8,9}$.

Although, the classical interrupted anastomosis technique, has already some disadvantages including leakage on clamp release which requires additional stiches, prolonged oozing duration and the longer time it requires for a successful anastomosis, which can be a compromising factor in prolonged cases of replantation or free tissue transfers ${ }^{5-7}$.

The most recent review of suture techniques in microvascular anastomosis shows that a statement cannot be made to favor either technique's patency rate and/or ease of performance when comparing endto-end and end-to-side configurations, mainly because there is no study in humans ${ }^{6}$. So, this study aims to comparing the continuous and interrupted suture technique in artery anastomosis in rats, search for influences at the patency and suture time after vessel repair and 14 days after.

\section{- Methods}

This study was approved by the Ethics Committee for the Use of Animals of the Universidade Estadual do Pará. This study following the Brazilian law of use and care of animals (Law $\mathrm{n}^{\circ} 11.794 / 08$ ).

Twenty male Wistar rats (Rattus norvegicus) obtained from the Animal Colony of the Experimental Surgery Laboratory of UEPA were used. They weighed 200-320g and were kept in a controlled environment with food and water ad libitum. The sample size was determined at the beginning of the study through specific statistical tests, based in previous studies ${ }^{6-9}$. The risk management standards $\alpha(5 \%)$ and $\beta(10 \%)$ were considered, as well as the diversity of variables.

The animals were randomly assigned into two groups: interrupted suture group (ISG, $n=10$ ), for which femoral artery were sutured with eight simple stitches (the first two knots were perform in the angles $0^{\circ}$ and $180^{\circ}$, and three points on the anterior and three on posterior wall on $60^{\circ}, 90^{\circ}$ and $150^{\circ}$ angles $)^{7-9}$, and continuous suture group (CSG, $n=10$ ), for which femoral artery were sutured with simple continuous suture (the first two knots were 
perform in the angles $0^{\circ}$ and $180^{\circ}$, using the line from the knot of the $0^{\circ}$ were performed the suture of the anterior wall, and from the knot of $180^{\circ}$ the posterior wall, ${ }^{6,9}$ (Figure 1 ).

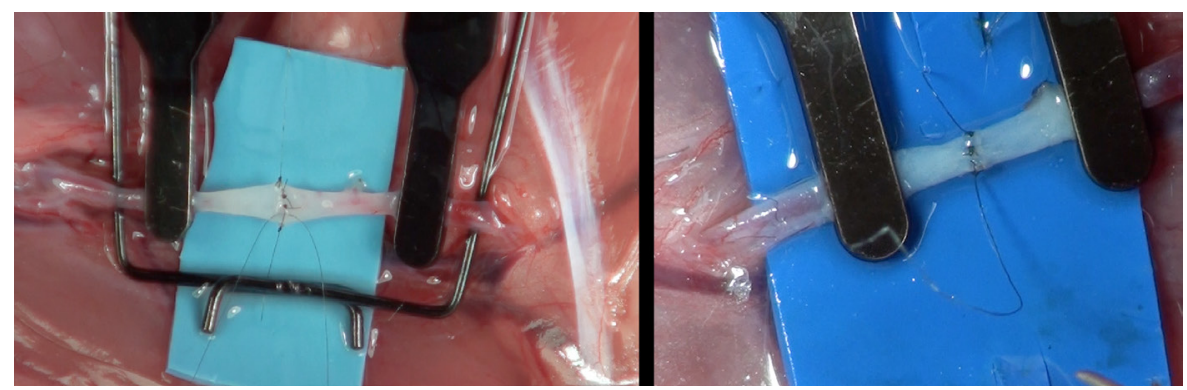

Figure 1 - Final aspect of anastomosis. Right - interrupted suture; Left - continuous suture.

The microsurgical procedures were performed under a DFVasconcelos ${ }^{\odot}$ microscope with an image magnification of $\mathrm{x} 40$ by the same surgeon (RSMB). All animals underwent the same surgical procedure, with the two groups differing only in the suture technique used. The rats were weighed and then anesthetized with ketamine $(80 \mathrm{mg} / \mathrm{kg}$ ) and xylazine $(10 \mathrm{mg} / \mathrm{kg})$ intraperitoneally and then shaved and placed in a horizontal supine position. Antisepsis was performed for all anterior hind legs. A longitudinal incision took place in the anterolateral place of the right member, from the major trochanter towards the lateral condyle of the femur, then the subcutaneous tissue was dissected and the femoral neurovascular bundle was identified and the structures were individualized. A blue rubber shield was used for better visualization of the vessels. Lidocaine $2 \%$ was used to prevent spasm ${ }^{10}$. At this moment, the external diameter of the femoral artery was measured by a digital caliper.

A double clamp was positioned and an arteriotomy was performed at the midpoint of the double clamp. The stumps were prepared by removal of the adventitia, dilation, and irrigation of the lumen with Tsay solution (200 $\mathrm{ml}$ of Ringer solution $+20 \mathrm{ml}$ of Lidocaine + $0.1 \mathrm{ml}$ of Heparine $5000 \mathrm{Ul} / \mathrm{ml}$ ). Clamps were approached and then sutured with the suture technique according the group using 10-0 nylon. Following the suture, the clamp was removed and the anastomosis patency was immediately tested by Acland test ${ }^{4,7-13}$. Skin synthesis was achieved through continuous suture using 5-0 nylon. Neither antibiotics nor systemic anticoagulants were used.

The animals were followed up by 14 days postoperatively. The animals were anesthetized and the final anastomosis permeability test was performed by Acland test ${ }^{4,7-13}$. The animals, still anesthetized, were euthanized by intravenous lethal injection.

The parameters analyzed were weight (grams), initial and final femoral artery diameter $(\mathrm{mm})$, suture time ( $\mathrm{min}$ ) and patency of anastomosis with the Acland test straight after vessel repair and 14 days after ${ }^{4,7-13}$ (pervious or not). BioEstat ${ }^{\odot} 5.4$ software was used for analyses. Student's t test was used to compare the numeric variables and the patency rate was compared using Fisher's exact test. The Pearson's correlation test was used to determine the association between the rat's weight and femoral artery caliber. We adopted a significance level of $5 \%$.

\section{Results}

No animal had complications or died during the follow up. The Table 1 shows the descriptive statistics analyze. There were no significant differences between the groups in 
the mean animals' weight (ISG: $244 \pm 35 \mathrm{~g}$ vs. CSG: $249 \pm 43$ g; $p=0,64$ ) or femoral artery caliber immediately after the anastomosis (ISG: $0,81 \pm 0,03 \mathrm{~mm}$ vs CSG: $0,80 \pm 0,02 \mathrm{~mm}$; $\mathrm{p}=0,95$ ) or 14 days after (ISG: $0,79 \pm 0,02 \mathrm{~mm}$ vs CSG: $0,78 \pm 0,02 \mathrm{~mm} ; \mathrm{p}=0,96)$. There were no significant differences between the initial and final arterial diameter. Correlation analysis showed no correlation between the animals' weight and femoral artery caliber $(p=0.68)$.

The mean time required to perform each arterial anastomosis was $718.72 \pm 41.59$ sec in ISG and $451.60 \pm 57.33 \mathrm{~min}$ in CSG. The difference between the groups was statistically significant $(p<0.01)$, which the continuous suture was faster than interrupted technique.

The immediate patency at was $100 \%$ in interrupted suture and $100 \%$ in continuous suture group, and the $14^{\text {th }}$ days patency was $100 \%$ in interrupted suture and $100 \%$ in continuous suture group. There is no significant differences between the groups in both evaluated time $(p=1.00)$.

Table 1 - Descriptive statistics data according the groups.

\begin{tabular}{|c|c|c|c|c|c|c|c|c|c|c|}
\hline \multirow{2}{*}{$\begin{array}{l}\text { Descriptive } \\
\text { statistics }\end{array}$} & \multicolumn{2}{|c|}{$\begin{array}{l}\text { Animals' } \\
\text { weight (g) }\end{array}$} & \multicolumn{2}{|c|}{$\begin{array}{l}\text { Vessel caliber } \\
(\mathrm{mm})\end{array}$} & \multicolumn{2}{|c|}{$\begin{array}{l}\text { Anastomosis } \\
\text { time (seg) }\end{array}$} & \multicolumn{2}{|c|}{$\begin{array}{l}\text { Immediate } \\
\text { patency }\end{array}$} & \multicolumn{2}{|c|}{ Late patency } \\
\hline & ISG & CSG & ISG & CSG & ISG & CSG & ISG & CSG & ISG & CSG \\
\hline Minimum & 203 & 202 & 0.75 & 0.75 & 612 & 361 & - & - & - & - \\
\hline Maximum & 288 & 293 & 0.85 & 0.85 & 884 & 601 & Positive & Positive & Positive & Positive \\
\hline Mean & 244 & 249 & 0.81 & 0.80 & 718.72 & 451.60 & Positive & Positive & Positive & Positive \\
\hline $\begin{array}{l}\text { Stardard } \\
\text { deviation }\end{array}$ & 35 & 43 & 0.03 & 0.02 & 41.59 & 57.33 & - & - & - & - \\
\hline $\begin{array}{l}\text { Coefficient of } \\
\text { variance }\end{array}$ & $34.76 \%$ & $36.54 \%$ & $12.34 \%$ & $11.52 \%$ & $37.88 \%$ & $23.21 \%$ & $0.00 \%$ & $0.00 \%$ & $0.00 \%$ & $0.00 \%$ \\
\hline
\end{tabular}

ISG - Interrupted Suture Group; CSG - Continuous Suture Group

\section{Discussion}

Several new techniques have been developed for microvascular repair to reduce the procedure time, such as laser ${ }^{11}$, glue ${ }^{12}$, intravascular stent ${ }^{13}$ and precise microvascular anastomotic system ${ }^{14}$. The major reasons for developing these alternative techniques are to reduce the time required to perform an anastomosis, an operation that takes up most of the time in a reconstructive microsurgical procedure, as well as the amount of suture material used, the trauma inflicted, and the likelihood of thrombosis; additionally, the elimination of size discrepancy, the reduction of costs, and the development of a technique that is relatively easy to learn and perform are other factors contributing to the development of these alternative techniques ${ }^{5,7-9}$.

However, the classic suture techniques have the better patency rate and results than these new technologies. The success of microvascular anastomosis and minimization of postoperative complications are related to exposition of adventitia and media; choice of suture material and needle; number of sutures; suturing technique; elimination of luminal occlusion linked to inversion, eversion, stenosis, thrombosis, and intimal thickening; and freeing the lumen from foreign material as well as atraumatic meticulous handling.

Currently, there are numerous suture techniques for microsurgical anastomoses described in the literature, such as sleeve, 
continuous, 4-suture eversion, Z-plasty anastomosis, modified sleeve anastomosis with 2 horizontal mattress sutures. These techniques aim to reduce the surgical time and keep the patency ${ }^{5-7,9}$.

There were no significant differences between the groups in the mean weight, caliber of femoral artery, or quantities of stitches when analyzed confirming the pairing of the groups. Our results show an advantage in use the continuous technique, since the both groups show the same patency rate, although the interrupted group has a surgical time 1.60 longer than continuous suture.

Usually, fat animals were used for training because it is believed that they have bigger vessels ${ }^{15,16}$, but in our data, there is no correlation between arterial diameter and weight. Showing a no advantage in using fatter rats, since they are older and it could affect the results of a researcher.

The main apprehension with the continuous suture is the possibility of increase the lumen stenosis carrying with low flow ${ }^{3,6,13}$. This study shows that there no difference between the suture techniques in the final lumen diameter ${ }^{17,18}$. Some author found the same result, showing that the lumen stenosis is similar independent of the suture technique.

The decision to perform a specific microvascular technique ultimately depends on surgeon preference, operative experience, and the availability of a suitable recipient target vessel. So, the continuous suture technique must be more stimulated on training center and on residency programs. Despite these encouraging results, this method should be evaluated by further human studies before it is clinically applied, mainly because normally the experimental studies, as this study, don't simulates the conditions of vascular injury that the vessel suffer as twisting and avulsion ${ }^{1-3,6,8}$.

The limits of this study were no evaluation of blood loss or histopathologic analysis ${ }^{9,13}$. They do not invalidate the results we achieved, but future studies should be designed in order to overcome them; as well as new studies comparing the differences continuous suture techniques. The patency evaluation is limited because the flowmetry was not measured; however, the analysis method used is widely used as the only patency evaluation method ${ }^{4,6-14}$.

\section{Conclusion}

The continuous suture technique shows a similar patency rates than interrupted technique, however with a shorter time to perform the anastomosis.

\section{References}

1. Martins PNA, Montero EFS. Basic microsurgery training: Comments and proposal. Acta CirBras. 2007 Jan;22(1):79-81. doi: 10.1590/S0102-86502007000100014.

2. Lima DA, Galvão MS, Cardoso MM, Leal PR. Laboratory training program in microsurgery at the National Cancer Institute. Rev Bras Cir Plást. 2012;27(1):141-9.

3. Kallás IE, Kallás AC, Kallás E. Arterial anastomosis: past, present and future. Acta Cir Bras. 1999 Oct;14(4):221-7. PMID: 8269136.

4. Aygun $H$, Yildirim OS. Vertical mattress suture technique: an alternative vascular anastomosis J Reconstr Microsurg. 2008 Aug;24(6):97-404. doi: 10.1055/s-00281082027.

5. Lin TS, Chiang YC. Combined microvascular anastomosis: experimental and clinical experience. Ann Plast Surg. 2000 Sep;45(3):280-3. PMID: 10987530.

6. Alghoul MS, Gordon CR, Yetman R, Buncke GM, Siemionow M, Afifi AM, Moon WK. From simple interrupted to complex spiral: a systematic review of various suture techniques for microvascular anastomoses. Microsurgery. 2011 Jan;31(1):72-80. doi: 10.1002/micr.20813.

7. Radad K, El-Shazly M. Clinical and pathological assessment of different suture 
techniques for microvascular anastomosis in rat femoral artery. J Vet Sci. 2007 Sep;8(3):269-73. PMID: 17679774.

8. Simşek T, Eroglu L, Engin MS, Kaplan S, Yildiz L. End-to-end microvascular anastomosis in the rat carotid artery using continuous horizontal mattress sutures. J Reconstr Microsurg. 2006 Nov;22(8):631-40. doi: 10.1055/s-2006-956237.

9. Chen YX, Chen LE, Seaber AV, Urbaniak JR. Comparison of continuous and interrupted suture techniques in microvascular anastomosis. J Hand Surg Am. 2001 May;26(3):530-9. doi: 10.1053/ jhsu.2001.22933.

10. Barros RS, Brito MV, Moura GP, Moura MP, Freitas LM, Silva KS, Leal RA. Is it possible to do a microvascular anastomosis with an ordinary video camera? Experimental study. J Reconstr Microsurg. 2011 Oct;27(8):503-8. doi: $10.1055 / \mathrm{s}-0031-1284237$.

11.Leclère FM, Vogt $P$, Schoofs $M$, Delattre M, Mordon S. Current laser applications in reconstructive microsurgery: a review of the literature. J Cosmet Laser Ther. 2016 Jun;18(3):130-3. doi: 10.3109/14764172.2015.1114640.

12.Langer S, Schildhauer TA, Dudda M, Sauber $\mathrm{J}$, Spindler N. Fibrin glue as a protective tool for microanastomoses in limb reconstructive surgery. GMS Interdiscip Plast Reconstr Surg
DGPW. 2015 Dec;4:Doc14. doi: 10.3205/ iprs000073.

13.Assersen K, Sørensen J. Intravascular stenting in microvascular anastomoses. J Reconstr Microsurg. 2015 Feb;31(2):113-8. doi: $10.1055 / \mathrm{s}-0034-1384812$.

14. Oguchi $H$, van der Lei $B$. The $3 M$ precise microvascular anastomotic system for implanting PTFE microvenous prostheses into the rat femoral vein. Plast Reconstr Surg. 1996 Mar;97(3):662-5.

15.Chan WY, Matteucci P, Southern SJ. Validation of microsurgical models in microsurgery training and competence: a review. Microsurgery. 2007;27(5):494-9. doi: 10.1002/micr.20393.

16. Hölzen JP, Palmes $D$, Langer $M$, Spiegel HU. Microsurgical training curriculum for learning kidney and liver transplantation in the rat. Microsurgery. 2005 Nov;25(8):61423. doi: 10.1002/micr.20174.

17.Schlechter B, Guyuron B. A comparison of different suture techniques for microvascular anastomosis. Ann Plast Surg. 1994 Jul;33(1):28-31. PMID: 7944193.

18.Sapountzis S, Kiranantawat K, Lim SY, Constantinides J, Ciudad P, Nicoli F, Wei MY, Sönmez TT, Chen HC. A novel "continuousinterrupted" method for microvascular anastomosis. Microsurgery. 2014 Jan;34(1):82-4. doi: 10.1002/micr.22174.

\section{Correspondence:}

Renan Kleber Costa Teixeira

Rua Mundurucus, 2256/1401

66035-360 Belém - PA Brasil

Tel.: (55 91)98145-1108

renankleberc@hotmail.com

Received: May 12, 2017

Review: July 14, 2017

Accepted: Aug 18, 2017
Conflict of interest: none

Financial source: none

\begin{abstract}
${ }^{1}$ Research performed at Laboratory of Experimental Surgery, Universidade do Estado do Pará (UEPA), Belem-PA, Brazil.
\end{abstract}

